\title{
CIUDAD Y EDUCACIÓN LAS SOCIEDADES DE MEJORAS PÚBLICAS Y LA CONSTRUCCIÓN DEL "ESPÍRITU CÍVICO”*
}

\author{
Carlos Ernesto Noguera**
}

\begin{abstract}
RESUMEN - La creación del "espiritu cívico", uno de los propósitos centrales de las Sociedades de Mejoras Públicas, implicó un amplio proceso de educación masiva, el primero y uno de los más importantes que haya conocido el siglo $\mathrm{XX}$. Así, en poco menos de medio siglo, tanto el paisaje urbano como sus habitantes, prácticas y costumbres cambiaron como no lo hicieron durante casi un siglo de vida republicana. Se trató, nada más y nada menos, que de formar el nuevo ciudadano, de enseñar a habitar la ciudad, a hacer uso de sus nuevos espacios, aparatos y máquinas, en fin, de crear en los sectores populares, nuevos hábitos, actitudes y preferencias.
\end{abstract} PALABRAS-CHAVE - ciudad, educación y espíritu civico
ABSTRACT - The creation of "civic spirit", one of the main purposes of the Publics Improvements Societys, involved a broad process of mass education, the first one and ones of the most important that have beer known of in the twenty century. That way, in a little shorter than half a century, the urban landscape as well as its inhabitants, habits and customs changed as never before during almost a century of republican life. An attempt was made to create nothing less - a new citizen, teaching how to dwell in the city, use it new spaces, devices and machines, in short to create among the popular segments new habits, attitudes and preferences. XEY WORDS - city, education and spirit civic.

“[...] todo ciudadano debe trabajar por el mejoramiento de su ciudad, porque así lo demanda su propia conveniencia y su propio decoro. ¿Cómo se consigue esto? Fundando en cada ciudad, en cada pueblo, una Sociedad de Mejoras Públicas."1

Uno de los acontecimientos más importantes en el proceso de construcción de la nueva ciudad y de su nuevo habitante, el ciudadano, tuvo que ver con la creación, por parte de sectores de las élites locales (particularmente empresarios, médicos, ingenieros y abogados), de Sociedades de Mejoras Públicas. La primera de

* La presente ponencia forma parte de los resultados de la investigación "Ciudad, Educación y Escuela. El caso de Bogotá y Medellín (1930-1956)". Cofinanciado por el Instituto para la Investigación Educativa y el Desarrollo (IDEP) de la Alcaldía Mayor de Santa Fe de Bogotá y las Corporaciones CEPCS y Sociedad.

** Investigador Sociedad Colombiana de Pedagogía, Magister en Historia e Miembro de la Asociación de Hist. de la Educación Colombiana.

1 OLANO, Ricardo. Propaganda cívica. Medellín: Bedout, 1930, p. 144.

\begin{tabular}{|l|l|l|l|l|l|}
\hline VERITAS & Porto Alegre & v. 43 & $\mathrm{n}^{0}$ especial & Dezembro 1998 & p. 123-129 \\
\hline
\end{tabular}


estas instituciones creada en Colombia fue la Sociedad de Embellecimiento y Mejoras Públicas de Bogotá (SEMPB), fundada en 1898; le siguió la Sociedad de Mejoras Públicas de Medellín creada al año siguiente.

Desde sus comienzos, estas instituciones, aunque de carácter particular, funcionaron como organismos consultores de las administraciones locales y dirigieron sus actividades hacia la construcción de lo que denominaron el "espíritu cívico".

Este artículo pretende analizar, precisamente, el proceso de construcción de ese "espíritu cívico", pues fue sin duda uno de los primeros y más importantes esfuerzos educativos no escolares desarrollados a comienzos de siglo $\mathrm{xX}$ cuya extensión alcanzó amplios sectores de población. Como estrategia educativa de carácter masivo, la conformación del espiritu cívico implicó el despliegue de diversos mecanismos que iban desde las publicaciones (revista, periódico) pasando por la elaboración de carteles y avisos, hasta conferencias, creación de instituciones educativas, proyectos urbanísticos y arquitectónicos, parques y otras obras públicas con claros propósitos formativos.

\section{El caso de la Sociedad de Mejoras y Omato de Bogotá: de Santa Fe a Bogotá}

Construir la ciudad moderna, urbanizar, era a la vez educar, construir el nuevo ciudadano. La preocupación por la estética del espacio urbano, por su embellecimiento, por su ornato, no puede verse como un simple capricho elitista, como una simple expresión del gusto moderno, burgués. Se trató, además y fundamentalmente, de un mecanismo a través del cual se pretendió imponer una imagen de ciudad y con ella nuevas formas de vida, nuevos hábitos, nuevas actitudes, nuevas preferencias. En fin, fue una acción con claros propósitos educativos, una educación de masas.

Los acontecimientos del 9 de abril de $1948^{2}$ se encargaron de dar el paso definitivo de la vieja Santa Fe, nombre con el que se conoció la ciudad durante el periodo colonial, a la Bogotá moderna en la medida en que la destrucción del centro histórico de la ciudad generó un intenso proceso de construcción de modernos edificios y ampliación de calles centrales. Jacques April-Gniset, uno de los estudiosos de este proceso en lo que tuvo que ver con la arquitectura, señala que después del 9 de abril soplaron nuevos vientos en materia de construcciones. Elementos novedosos como el acero para las estructuras metálicas, el vidrio, los ascensores, permitieron generalizar en el centro de Bogotá el edificio tipo torre, concebido según la tecnología norteamericana del concreto. ${ }^{3}$ Contando con el apoyo económico norteamericano, la ciudad capital comenzó a abandonar sus estructuras neo-clásicas y la marcada influencia europea por modelos norteamericanos que representaban lo más moderno en el mundo.

2 En esta fecha fue asesinado el caudillo popular Jorge Eliécer Gaitán, líder de una fracción del partido liberal. Una vez se conoció la noticia del homicidio, amplios sectores populares iniciaron una revuelta que llevó a la destrucción parcial del centro del Bogotá. Este acontecimiento se conoce en la historia nacional con el nombre de "El Bogotazo".

3 APRLE-GNISET, Jacques. La ciudad colombiana. Siglo XIX y siglo XX. Bogotá: Biblioteca Banco Popular, 1992, p. 641. 
Pero aunque en sus mismos nombres - Sociedad de Embellecimiento y Mejoras Públicas de Bogotá y Sociedad de Mejoras y Ornato de Bogotá - la institución cívica bogotana señalara el énfasis de sus acciones, su labor se extendió hacia otros ámbitos de la propaganda cívica: además de su revista (llamada Santa Fe y Bogotá, quizá intentando señalar la época de transición en que se encontraba la ciudad por esos años) y otras publicaciones que realizó, compró y readecuó la Quinta del Libertador Simón Bolívar como monumento histórico y símbolo de patriotismo; construyó y readecuó varios parques, plazas y jardines (elementos de salud, esparcimiento y uso del tiempo libre); fomentó la construcción de avenidas y ampliación de calles (como la avenida Caracas, primera gran avenida moderna de la ciudad); promovió la "higienización" del Paseo Bolívar, sector de los cerros orientales de la ciudad habitado por gentes de muy escasos recursos; realizó una amplia labor de arborización de la ciudad; compró varios terrenos para permitir el ensanche de calles y la construcción de plazas, así como la edificación de escuelas; promovió la autonomia administrativa y fiscal de Bogotá; se preocupó por la estética de las edificaciones mediante propuestas para la regulación de construcciones; erigió varios monumentos, reubicó y recuperó otros; impulsó diversas acciones higiénicas, en particular de teatros y cafés, sitios de concurrencia masiva; propenđió por la organización del tráfico automotor en la ciudad y su regulación; fomentó la creación de bombas de gasolina e ideó un impuesto para inversión en obras públicas; instauró diversos premios como la medalla al civismo, el premio anual a los inspectores municipales de barrios; contribuyó al establecimiento de fiestas y celebraciones patrias y en alguna ocasión creó un premio de una copa de plata que disputarian cada año los equipos de fútbol de la ciudad (debe tenerse en cuenta que éste era uno de los deportes modernos que gozaba de gran prestigio en Europa y otros países latinoamericanos).

Una de las actividades a las que la SMOB dedicó particular atención fue la construcción y recuperación de parques y plazas; a través de estas obras, la SMOB influyó en la alteración del tiempo libre, especialmente el de los días domingo, cuando las familias podian disfrutar de las famosas retretas, juegos, paseos en bote y bailes populares al aire libre. Este es un hecho de gran importancia, pues se trató de la creación de nuevos espacios públicos de socialización y de nuevas formas de recreación y uso del tiempo libre.

Hacia la década del treinta se percibe una considerable presencia de estos espacios públicos en la ciudad: además del nuevo Parque Nacional Olaya Herrera, estaban el parque de Lunapark, al sur de la ciudad, el parque Gaitán y el parque de El Lago. Estos nuevos lugares, en tanto espacios abiertos, arborizados e higiénicos, contrastaban con las chicherias, ${ }^{4}$ pasajes y demás edificaciones "antihigiénicas" utilizadas popularmente como espacios de socialización y diversión. De ahí su importancia en el proceso de construcción de la urbe moderna.

Sólo hasta 1942, se contaba la intervención de 11 de estos sitios por parte de la SMOB, entre los cuales vale la pena mencionar el Parque del Centenario, el Parque Santander, el Parque España, el Parque de la Independencia y el Parque de Los Mártires. Años más tarde, la SMOB emprendería una lucha por la recuperación

4 Expendios de chicha, bebida popular de origen indigena elaborada con base en maíz fermentado. 
de estos espacios, pues por efecto del crecimiento del parque... automotor, varios de estos sitios se convirtieron en parque... aderos. Ya en el mismo año de 1942, se reclamaba que después de las obras de recuperación realizadas en el parque Santander, "la Sociedad no ha podido hacer más que limitarse a pedir en todos los tonos que no se convierta este parque central en un estacionamiento de vehículos." Muchos años después continuaba el clamor: en la sesión del 27 de mayo de 1959 el socio Patino Galvis hizo algunas aclaraciones sobre proposiciones presentadas por él en sesiones anteriores y que tenian que ver con la recuperación del parque de Los Mártires como jardín público, pues se había convertido en paradero de buses "y en punto de reunión de maleantes, culebreros, ${ }^{6}$ etc., que esperan a los campesinos para tratar de engañarlos y robarlos, pues la mayoría de tales buses proceden de diferentes poblaciones cercanas a Bogotá." Además, proponía la "construcción de un jardín público en la Plaza de Nariño, que fue convertida por el antiguo Municipio de Bogotá, contra el querer de la ciudadanía, en estacionamiento o parqueadero."?

Desde 1946 la SMOB extendió sus campañas cívicas a través de la radio. El 30 de enero de ese año, el gerente de la emisora Radio Continental ofreció una hora semanal gratuita a la SMOB "Como cooperación a las importantes campañas cívicas que tan respetable entidad viene desarrollando en pro de la ciudad capital." Este programa, inaugurado el 24 de abril de 1947, se llamó "Habla Bogotá" y se transmitía los miércoles a las 9 y 30 p. m. La acción se extendió también a través del cinematógrafo, mediante avisos de exhortación cívica proyectados antes de las películas. Pero aún más, se extendió hacia el cinematógrafo, valga decir, hacia los espacios de proyección y sus asistentes.

Si bien en los años cuarenta asistir al cinematógrafo era ya una práctica común de miles de bogotanos, los comportamientos en estos lugares públicos, a la mirada de las élites, no eran precisamente los más apropiados. En diversas ocasiones, los miembros de la SMOB manifestaron su preocupación por la forma "inculta" como procedían los asistentes a las funciones. El asunto era entonces, bastante inquietante como lo muestra una ponencia presentada en el III Congreso Nacional de Sociedades de Mejoras Públicas. Bajo el título de "Teatros y cinematógrafos", un empresario reconocía:

\footnotetext{
"Capítulo extenso, y no menos útil, podria escribirse acerca de la educación del público en los teatros. Si no fuera tan doloroso el contraste entre lo que aquí vemos y lo que suele verse en tierras de más refinada cultura, haríamos una composición de lugar para llegarnos una noche a la sala de uno de aquellos teatros. No importa que se trate de ópera, de come- dia o de cine; la cultura es la misma, no depende del espectáculo, sino de las costumbres, es decir, del público. La sala está colmada, y sin embargo, apenas si se oye un leve murmullo de discretas voces que cesan en cuanto ia orquesta, a la hora exacta del programa, deja oír sus primeros acordes. Las puertas quedan guardadas por ujieres que prohiben en absoluto la entrada una vez que la función haya empezado. Durante el espectáculo es pro-

5 Boletín de la Sociedad de Mejoras y Ornato, Bogotá, n. 70, p. 37, mar. 1942.

6 Se llama así a los vendedores callejeros de mercancías menores que para llamar la atención de los transeuntes y promocionar sus artículos recurren a una muy particular serie de frases, expresiones,

7 Sociedad de Mejoras y Ornato de Bogotá. Acta de la sesión del 27 de mayo de 1959.

8 Santa Fe y Bogotá, Bogotá, n. 6-7, p. 29, ene./feb., 1946.
} versos y refranes populares. 
hibido, por ley de la costumbre, aplaudir a destiempo y hacer cualquier manifestación extemporánea o ruidosa, fuera del aplauso mesurado y oportuno. Es tal la compostura del público, que la estridencia de un grito sonaría allí como el más punible de los desacatos.

Vengamos ahora a lo nuestro. Las gentes entran durante el acto, hacen terrible trajin de asientos; molestan al vecino de luneta sin darle excusas al entrar, y es de tal laya el estruendo de aplausos y risotadas, cuando el caso viene, que los mismos actores, si no conocen ya el género de cultura que tienen por delante, se asombran de oir que los aplauden a gritos, y les exigen la repetición con voces que no habian oído en ningún teatro.

Nadie asiste puntualmente a los espectáculos (salvo los cines, a cuyas empresas es forzoso abonarles esa buena nota). Los empresarios saben que el público, por viejo resabio, no acude jamás a la hora de programa, y el público sabe, de su lado, que nunca las funciones empiezan cuando deben, de donde se ha originado un circulo vicioso que podría y deberían romper las autoridades, si las autoridades estuvieran educadas para darle importancia a la cultura de la exactitud [...].

A todo esto hay que agregar la costumbre, tolerada aquí tranquilamente, de fumar en los salones de cine, de tal suerte que a la media hora de empezada una función el ambiente está lleno de humo y el aire enrarecido... Las Sociedades de Mejoras Públicas pueden y deben llevar esa lucha sobre si por medio de la prensa; por indicaciones a las autoridades, por insistentes súplicas a las empresas, y por insinuaciones directas al público, ya que tales sociedades han sido instituidas para velar por el mejoramiento cultural de los pueblos."

En esta extensa nota es posible apreciar varios aspectos de interés para el análisis de la acción educativa emprendida por las SMP. En primer lugar, como lo anota el autor de la cita, la asistencia a estos espectáculos públicos requiere o exige el cumplimiento de ciertas normas de comportamiento, hecho que se califica como "refinada cultura". Este refinamiento en los comportamientos tiene que ver con una cierta idea de tiempo expresada en la puntualidad, en la manifestación oportuna de ciertas expresiones y sobre todo, en el control de la sensibilidad y la expresividad, conductas que aparecen ligadas a los valores más modernos y "civilizados", propios de cualquier ciudad que se precie de tal. Se aprecia asi de manera clara la pretensión "educativa" de las élites, valga decir, su intención por transformar los hábitos y formas de ser de los sectores populares en función de lo que se considera moderno, culto y civilizado.

Esa sensibilidad moderna de las élites se ve permanentemente provocada por las formas como la mayoría de la población hacía uso de la ciudad y su inmobiliario. En una nota del No. 2 de Santa Fe y Bogotá de 1946, uno de estos sensibles caballeros anotaba:

\footnotetext{
"VENTLACION. Es frecuente el caso de ver en los tranvías, personas de uno y otro sexo que vistiendo traje de civilizados y no siendo recién llegados de tribus bárbaras, lo primero que hacen es cerrar las vidrieras para que en el carro se forme un pesado ambiente de humo de mal tabaco, humanidad aglomerada, sudor de pies y axilas y aliento pesado. No se concibe que haya gente que guste de respirar semejante ambiente, pero asi pasa con suma frecuencia." ${ }^{10}$
}

Fijémonos que ni siquiera se juzga el hecho de fumar en el tranvia, lo que incomoda es que se trate de "mal tabaco". Podriamos continuar mencionando otras

\footnotetext{
9 GAVIRIA, J. A. Teatros y cinematógrafos. En: Tercer Congreso de Mejoras Públicas reunido en Medellin del 15 al 22 de agosto de 1934. Bogotá: Imp. Nacional, 1935, p. 223-224.

10 Santa Fe y Bogotá, Bogotá, n. 2, p. 12, sep. 1945.
} 
prácticas comunes que fueron vistas como propias de "tribus bárbaras" y no de habitantes de una ciudad del siglo xx, pues la lista es bastante amplia. Por el momento una más. Por Acuerdo 36 de 1919 se prohibió a las Agencias Mortuorias la exhibición de ataúdes y demás objetos funerarios, hecho corriente desde hacia mucho tiempo. Sobre esto punto aparecen varias notas en Santa Fe y Bogotá, una de ellas en No. 1 de agosto de 1945 en donde bajo el titulo de Exposiciones Macabras, aparece el siguiente comentario:

"Se ha llamado la atención del alcalde de la ciudad a la necesidad de hacer efectivo el
acuerdo municipal por el cual se prohibe terminantemente la exhibición de ataúdes y de-
más objetos funerarios, en las agencias mortuorias y otros sitios. Tales artículos no deben
tenerse a la vista del público, bajo ningún pretexto."11

Años más tarde, en el oํ 13 de marzo de 1947 aparece una nueva nota insistiendo sobre el asunto y proponiendo que se expida un nuevo acuerdo por medio del cual se obligara a tales agencias "a tener sitios especiales, privados, en donde tuvieran en depósito sus artículos, y que sus actuales locales solamente sirvieran de oficinas para atender al público y de ninguna manera de muestrario de objetos funerarios." Estas exposiciones macabras eran ante todo, antiestéticas, muestra de mal gusto. La muerte, los objetos mortuorios y sus rituales debían permanecer en el ámbito de la privacidad.

El vestido fue otro de los puntos hasta donde llegó la mirada escrutadora de las élites. Baste mencionar las medidas tomadas por el alcalde Jorge Eliécer Gaitán en 1936 sobre la indumentaria de los funcionarios de la alcaldía y los conductores de servicio público. ${ }^{12}$ Desde luego, la SMOB también se ocupó de este asunto; en una de sus sesiones "se discutió sobre la reforma de la indumentaria del pueblo en lo relativo a la ruana."13

En conclusión, y desde esta perspectiva, podríamos decir que el proceso de construcción de las ciudades modernas requirió un amplio esfuerzo educativo por parte de sectores de la naciente burguesía quienes inspirados y deslumbrados con

11 Santa Fe y Bogotá, Bogotá, n. 1, p. 29, ago. 1945.

12 Aunque no hayan tenido aplicación inmediata, los decretos de Gaitán señalan el empeño por modernizar las formas de vestir del pueblo. El Decreto 333 de 1936 establece: "Art. $1^{\circ}$ Todos los obreros al servicio del Municipio estarán obligados a vestir decorosamente usando zapatos y vestido apropiado [...]. Art. $4^{Q}$ Estará impedido para trabajar en las dependencias del Municipio el obrero que no use calzado y vestido conveniente [...]." Otro decreto, el 425 de ese mismo año, obligaba a los choferes de servicio público a estar calzados "con zapatos de cuero, llevar bobina de estilo militar y blusa especial de trabajo u overol, de elección voluntaria".

13 Boletín de la sociedad de Embellecimiento, Bogotá, n. 51, p. 386, mar. 1927. La ruana es una prenda de larga tradición popular elaborada en lana de oveja y cuya base fue la capa usada por los españoles en la época colonial. Como se puede constatar desde hace varias décadas, la modernidad ganó la guerra contra la ruana, pues su presencia en la ciudad ha quedado reducida al espacio de la casa o las calles de los barrios apartados en donde la provincia se niega a morir; sin embargo, es posible ver todavía en pleno centro de la ciudad algún despitado "ciudadano" portando, sin pena ni gloria, ese símbolo de otros tiempos. Se ganó la guerra, hemos dicho, pero para ello se requirieron varios siglos, pues tenemos noticias que desde finales del siglo XVIII se había iniciado esta guerra con la expedición del Reglamento para la buena administración de los oficios artesanos elaborado por Manuel Díaz de Hoyos a petición del virrey Espeleta y presentado el 26 de julio de 1789. Alli, en uno de sus artículos se señalaba el uso de esta cálida y acogedora prenda como práctica antihigiénica y sospechosa, pues iquien sabe que cosas se ocultaban debajo de aquesta! 
la luces de la modernidad europea y norteamericana, emprendieron grandes campañas (cruzadas al decir de algunos de ellos) por la creación y consolidación del "espíritu cívico". Se intentó así despertar en los sectores populares y en algunos sectores tradicionalistas y conservadores de las élites locales, un sentimiento de "amor" por la ciudad que debía reflejarse en la modificación, abandono y adquisición de nuevos comportamientos, hábitos y costumbres; es decir, se trató de la puesta en marcha de un proceso educativo por medio del cual se pretendió moldear el "ciudadano moderno", como el nuevo habitante que requerían las transformaciones urbanas de comienzos de siglo.

La creación de ese espíritu civico y de ese nuevo habitante de la ciudad, implicó un amplio proceso de educación masiva, el primero y uno de los más importantes que haya conocido el siglo $\mathrm{xx}$, tanto por sus propósitos y medios empleados, como por sus alcances. Así, en poco menos de medio siglo, tanto el paisaje urbano como sus habitantes, prácticas y costumbres cambiaron como no lo hicieron durante casi un siglo de viđa republicana. Costumbres y hábitos centenarios como el consumo de chicha, el uso de ruana y alpargatas (calzado popular elaborado a partir del procesamiento de una fibra vegetal) desaparecieron; por otro lado, prácticas como el baño diario, el uso de calzado, cierto tipo de prendas y su lavado constante, hicieron su aparición. Ir al parque, asistir al cinematógrafo, escuchar la radio, hablar por teléfono, transportarse en tranvía, bus o taxi, fueron otras de las no menos importantes actividades que bogotanos y paisas (así se llama a los habitantes de Medellín) debieron aprender.

Podríamos decir entonces que la transformación más importante durante este período y en la que estuvo comprometida una intensa y extensa acción educativa, tuvo que ver con las formas de vida de amplios sectores de la población: se trató, nada más y nada menos que de aprender a habitar la ciudad, a hacer uso de sus nuevos espacios, aparatos y máquinas. Todo un despliegue tecnológico tanto en el orden técnico, más bien evidente (tranvias, buses y automóviles particulares, teléfonos, cinematógrafo, radio), como en el orden social, menos visible pero igualmente efectivo: la casa, el hogar, la nueva familia.

\section{Referencias bibliográficas}

ACTAS de las sesiones de la Sociedad de Mejoras y Ornato de Bogotá, 1927-1950.

ALVAREZ, Alejandro, CASTRO, Jorge Orlando; NOGUERA, Carlos. Ciudad, educación y escuela. El caso de Bogotá y Medellín 1936-1950. Santa Fe de Bogotá: IDEP, CEPECS, SOCOLPE, 1997 (en imprenta).

APRIE-GNISET, Jacques. La ciudad colombiana. Siglo XIX y siglo XX. Bogotá: Biblioteca Banco Popular, 1992, p. 641.

BOLETIN de la Sociedad de Embellecimiento de Bogotá, 1927.

BOLETín de la Sociedad de Mejoras y Omato de Bogotá, 1942.

BOTERO HERRERA, Fernando. Medellín 1890-1950. Historia urbana y juego de intereses. Medellin: Editorial Universidad de Antioquia, 1996.

GAVIRIA, J. A. "Teatros y cinematógrafos". En: Tercer Congreso de Mejoras Públicas reunido en Medellin del 15 al 22 de agosto de 1934. Bogotá: Imprenta Nacional, 1935, p. 223-224.

OLANO, Ricardo. Propaganda cívica. Medellin: Bedout, 1930, p. 144.

SANTA Fe y Bogotá, Revista de la Sociedad de Mejoras y Ornato de Bogotá, 1946-1949. 
la luces de la modernidad europea y norteamericana, emprendieron grandes campañas (cruzadas al decir de algunos de ellos) por la creación y consolidación del "espíritu cívico". Se intentó así despertar en los sectores populares y en algunos sectores tradicionalistas y conservadores de las élites locales, un sentimiento de "amor" por la ciudad que debía reflejarse en la modificación, abandono y adquisición de nuevos comportamientos, hábitos y costumbres; es decir, se trató de la puesta en marcha de un proceso educativo por medio del cual se pretendió moldear el "ciudadano moderno", como el nuevo habitante que requerían las transformaciones urbanas de comienzos de siglo.

La creación de ese espíritu cívico y de ese nuevo habitante de la ciudad, implicó un amplio proceso de educación masiva, el primero y uno de los más importantes que haya conocido el siglo $\mathrm{xx}$, tanto por sus propósitos y medios empleados, como por sus alcances. Así, en poco menos de medio siglo, tanto el paisaje urbano como sus habitantes, prácticas y costumbres cambiaron como no lo hicieron durante casi un siglo de vida republicana. Costumbres y hábitos centenarios como el consumo de chicha, el uso de ruana y alpargatas (calzado popular elaborado a partir del procesamiento de una fibra vegetal) desaparecieron; por otro lado, prácticas como el baño diario, el uso de calzado, cierto tipo de prendas y su lavado constante, hicieron su aparición. Ir al parque, asistir al cinematógrafo, escuchar la radio, hablar por teléfono, transportarse en tranvía, bus o taxi, fueron otras de las no menos importantes actividades que bogotanos y paisas (así se llama a los habitantes de Medellín) debieron aprender.

Podríamos decir entonces que la transformación más importante durante este período y en la que estuvo comprometida una intensa y extensa acción educativa, tuvo que ver con las formas de vida de amplios sectores de la población: se trató, nada más y nada menos que de aprender a habitar la ciudad, a hacer uso de sus nuevos espacios, aparatos y máquinas. Todo un despliegue tecnológico tanto en el orden técnico, más bien evidente (tranvías, buses y automóviles particulares, teléfonos, cinematógrafo, radio), como en el orden social, menos visible pero igualmente efectivo: la casa, el hogar, la nueva familia.

\section{Referencias bibliográficas}

ACTAS de las sesiones de la Sociedad de Mejoras y Omato de Bogotá, 1927-1950.

ALVAREZ, Alejandro, CASTRO, Jorge Orlando; NOGUERA, Carlos. Ciudad, educación y escuela. El caso de Bogotá y Medelín 1936-1950. Santa Fe de Bogotá: DEP, CEPECS, SOCOLPE, 1997 (en imprenta).

APRILE-GNISET, Jacques. La ciudad colombiana. Siglo XIX y siglo XX. Bogotá: Biblioteca Banco Popular, 1992, p. 641.

BOLETíN de la Sociedad de Embeliecimiento de Bogotá, 1927.

BOLETÍN de la Sociedad de Mejoras y Omato de Bogotá, 1942.

BOTERO HERRERA, Fernando. Medellin 1890-1950. Historia urbana y juego de intereses. Medellín:

Editorial Universidad de Antioquia, 1996.

GAVIRIA, J. A. "Teatros y cinematógrafos". En: Tercer Congreso de Mejoras Públicas reunido en Medellin del 15 al 22 de agosto de 1934. Bogotá: Imprenta Nacional, 1935, p. 223-224. OL.ANO, Ricardo. Propaganda cívica. Medellín: Bedout, 1930, p. 144.

SANTA Fe y Bogotá, Revista de la Sociedad de Mejoras y Omato de Bogotá, 1946-1949. 